Click www.researchjournal.co.in/online/subdetail.html to purchase.

\title{
Economic and potential profitability assessment of poultry farming
}

\author{
V. B. Gholap, S. R. Benke and S. N. Patil
}

Received : 21.05.2020; Revised : 06.09.2020; Accepted : 18.09 .2020

\begin{abstract}
India today is the one of the world's largest producer of eggs and broiler meat. The poultry industry in India has undergone a major shift in structure and operation during the last two decades transforming from a mere backyard activity into a major industry with the presence of a large number of integrated players. Present study was conducted to examine the economic and potential profitability assessment of poultry farming. The study was based on the data collected from the primary source. The results revealed thatthe total fixed cost in RIR breed and Kadaknath breed were estimated to be Rs. 55.66 per bird and Rs. 50.61 per bird, respectively. Feed cost was the major cost item accounting 57 per cent of the total cost. BCR, IRR and PI of the project were 1.56, 57 per cent and 2.57, respectively. Similarly, NPW of the project was also positive. Project recovered its initial investment in one year one month 28 days. It shows that, this project is financially feasible.
\end{abstract}

KEY WORDS : Poultry farming, BCR, IRR, NPW, PI, BEP, Financial feasibility

How to cite this paper: Gholap, V.B., Benke, S.R. and Patil, S.N. (2020). Economic and potential profitability assessment of poultry farming. Internat. J. Com. \& Bus. Manage, 13(2) : 63-68, DOI: 10.15740/HAS/IJCBM/13.2/63-68. Copyright@2020: Hind AgriHorticultural Society.

E-mail: vaishali_bharat@rediffmail.com

\section{Authors' affiliations:}

S.R. Benke and S.N. Patil, Dr. D. Y. Patil College of Agriculture Business Management, Akurdi, Pune (M.S.) India 